\title{
LAS DISPUTAS EN TORNO A LA DESIGNACIÓN DE VEEDORES EN EL GREMIO DE LOS PELAIRES. MuRCIA, 1450-1510
}

\author{
MAURo FAZZINI ${ }^{1}$ \\ Universidad de Buenos Aires
}

Recibido: 7 de septiembre de 2019

Aceptado: 6 de agosto de 2020

\begin{abstract}
Resumen
En el presente trabajo nos proponemos analizar las tensiones existentes, entre mediados del siglo XV y principios del XVI, dentro del gremio murciano de los pelaires en torno a la designación anual de sus autoridades principales, los veedores. En este período, la elite dirigente busca hacerse con el monopolio del cargo en cuestión, mientras que un sector del artesanado resiste esta afrenta. A raíz de este conflicto, las autoridades urbanas modifican en diversas ocasiones los criterios de elección de veedores con el fin de acallar las tensiones internas de la corporación, aunque sin mayor éxito. Será nuestro objetivo analizar la naturaleza social de la disputa, para lo cual trataremos de identificar los intereses de los actores en pugna.
\end{abstract}

\section{Palabras clave}

Gremio, veedores, pelaires, cardadores, tundidores.

\begin{abstract}
This paper aims to analyze the existing tensions within the wool carders' guild of Murcia regarding the annual election of their main authorities - the so-called veedores - from the second half of the fifteenth century to the early sixteenth century. In this period, the guild's elite sought to monopolize the designation of these authorities, with the resistance of several guild members. As a consequence of this conflict, the local council interceded several times by changing the election system with the aim of calming the tensions, although with no success. Our objective is to identify the interests of the main actors involved in the conflict, in order to analyze the social nature of this dispute.
\end{abstract}

\section{Key words}

Craft guild, veedores, wool carders, shearers.

\section{Résumé}

L'objet de cette étude est d'analyser le conflit découlant de l'élection annuelle des contrôleurs au sein de la corporation des laineurs murciens du milieu du XVème siècle au début du XVIème. Pendant cette période, les dirigeants de la corporation essaient de monopoliser la désignation de postes de

1 Instituto de Historia Antigua y Medieval "José Luis Romero", Facultad de Filosofía y Letras, UBACONICET. Correo electrónico: maurofazzini89@gmail.com. ORCID: https://orcid.org/0000-0001-6482-7611. 
pouvoir, mais une grande partie des artisans s'oppose à cette prétention. En conséquence, le Conseil de ville modifie à plusieurs reprises les mécanismes d'élection des autorités corporatives pour apaiser le conflit, mais sans succès. On se propose d'analyser la nature sociale de ce différend et d'identifier les objectifs de ses protagonistes.

\section{Mots clés}

Corporation des métiers, contrôleurs, laineurs, cardeurs, tondeurs.

\section{Introducción}

En el presente trabajo nos proponemos analizar las tensiones existentes entre mediados del siglo XV y principios del XVI dentro del gremio murciano de los pelaires en torno a la designación anual de sus autoridades principales, los veedores ${ }^{2}$. Desde fines del siglo XIV, los miembros del gremio murciano de los pelaires se reúnen anualmente en el seno del cabildo gremial con el objeto de elegir a dos artesanos para que se desempeñen como autoridades del oficio. Una vez electos deben ser presentados ante los regidores alrededor del 24 de junio, fecha en la que se da inicio al año concejil. En un primer momento, al menos en función de la evidencia empírica disponible, la designación de autoridades no presentaría mayores conflictos ${ }^{3}$.

Es a partir de la segunda mitad del siglo XV cuando la elección de autoridades comienza a ser objeto de disputa entre una elite dirigente que tiende a monopolizar el cargo y un sector de la corporación que resiste este avance. Producto de este conflicto, que se extiende hasta comienzos del siglo XVI, las elecciones de veedores generan una coyuntura de inestabilidad en el interior del gremio. Frente a esto, las autoridades municipales pasan a intervenir en el proceso electoral, alterando los métodos de selección con la intención de bajar el nivel de conflictividad, aunque sin mayor éxito. De ahí que se asista a una modificación permanente de los criterios de designación de autoridades durante el período analizado.

Será nuestro objetivo indagar en la naturaleza social de este conflicto, para lo cual trataremos de identificar, hasta donde la documentación lo permita, los intereses concretos de los actores en pugna. Para ello tendremos en cuenta el carácter heterogéneo del gremio pelaire. En su seno, una elite de acumuladores capitalistas, mayormente abocados

\footnotetext{
2 La pelairía es uno de los oficios fundamentales del proceso productivo textil. Esta se encuentra abocada a diversas tareas relativas a la finalización del paño, una vez que este ha sido tejido. Los pelaires se ocupan de limpiar el paño de las impurezas adheridas durante el proceso productivo. Esta actividad se realiza en molinos hidráulicos que poseen mazas para golpear el paño mientas se encuentra sumergido en agua mezclada con elementos desengrasantes. Luego, este se cuelga para ser cardado. Dicha actividad consiste en recorrer ambas caras del paño todavía húmedo con cardas para eliminar el pelo sobrante, lo que dota al paño de un mejor acabado. Para mayores precisiones sobre el proceso técnico ver MarTíneZ Martínez, La industria del vestido en Murcia (siglos XIII-XV); Iradiel, Evolución de la industria textil castellana en los siglos XIII-XVI. Entre otros.

3 GonzÁlez Arce, Gremios, producción artesanal y mercado, p. 32.
} 
a tareas de coordinación y gestión, convive con artesanos asalariados de diverso tipo incapaces de elaborar paños por cuenta propia ${ }^{4}$. Estos últimos trabajan al servicio de la elite del gremio o bien de otros vecinos de la ciudad, generalmente mercaderes, que también elaboran paños para su venta. Partiendo de esta caracterización, trataremos de dilucidar hasta qué punto la disputa en torno a la veeduría obedece a la lógica de la lucha entre fracciones del empresariado pelaire; o bien si responde al antagonismo entre la elite pelaire en su conjunto y los artesanos asalariados del gremio.

Antes de proceder con el análisis, debemos exponer mínimamente cuáles son los atributos de la veeduría para así poder entender qué es lo que está en juego en cada elección. Quienes la ejercen son las máximas autoridades de la corporación y como tales llevan adelante una serie de tareas vinculadas a garantizar la calidad de la producción textil y la disciplina al interior del gremio. Para ello tienen la potestad de inspeccionar los obradores de los artesanos con el fin de constatar que su labor sea realizada de manera acorde a lo prescrito por las normas productivas de la corporación. Aquellos menestrales que violen las ordenanzas gremiales pueden ser sancionados por los veedores e incluso expulsados si la gravedad de la falta así lo ameritara. Asimismo, los veedores están encargados de examinar a aquellos aprendices que, concluido el período de formación, deseen ingresar al oficio. Esto permite certificar que los nuevos miembros del gremio posean el conocimiento necesario para el desempeño de su métier.

Es particularmente relevante el control ejercido sobre la mano de obra dependiente, subordinada dentro de la corporación. En adición al control y reglamentación de su proceso de trabajo, las autoridades gremiales estipulan sus niveles salariales. De esta manera, la dirección gremial es un elemento clave en la construcción de la jerarquía productiva en el interior de la corporación's.

En adición a estas tareas, los veedores del oficio de los pelaires, al menos desde la década de 1440, reciben del concejo ciertas atribuciones que exceden a su jurisdicción original. Así, quedan encargados de supervisar la calidad de la producción textil importada, esencial para complementar a la producción de la ciudad y lograr así el abastecimiento del mercado local. En paralelo, estos son facultados para examinar la labor de artesanos ajenos a su gremio, como los tejedores ${ }^{6}$.

Por último, quienes detentan la veeduría, en tanto ejercen la dirección del gremio, actúan como representantes del oficio ante las autoridades municipales. Así, se ven implicados en diversas negociaciones con los regidores de la ciudad que abarcan los temas más

\footnotetext{
4 Hemos estudiado el proceso de conformación de la elite de empresarios pelaires en, FAZZINI, "La construcción de la hegemonía pelaire en la protoindustria textil murciana". A la vez se da cuenta de la existencia de un núcleo pelaires acaudalados para el caso murciano en MARTínez MARTínez, La industria del vestido en Murcia (siglos XIII-XV); GonzÁlez ArCE, Gremios, producción artesanal y mercado.

5 Córdoba de la Llave, "Guild Authorities in Late Medieval Spain"; Córdoba de la Llave, Los oficios medievales; Martínez Martínez, La industria del vestido en Murcia (siglos XIII-XV); GonzÁlez Arce, Gremios, producción artesanal y mercado.

6 Hemos analizado este proceso en FAzZINI, "La construcción de la hegemonía pelaire en la protoindustria textil murciana".
} 
diversos; precios y salarios, la elaboración de ordenanzas productivas, la instrumentación de medidas que restrinjan la competencia foránea, entre otros. De esta manera, la veeduría resulta fundamental, tanto para establecer la disciplina hacia el interior del gremio, como para representar los intereses de la corporación frente a las autoridades municipales. De ahí que sea codiciada por los miembros del oficio.

\section{Elecciones de veedores y alteración permanente de los mecanismos de designación}

Como mencionamos en la introducción, es a partir de la segunda mitad del siglo XV cuando podemos encontrar evidencias sobre los conflictos acaecidos en torno a la designación de las autoridades gremiales de los pelaires. En 1460, los veedores en ejercicio se presentan ante el concejo para señalar la existencia de

escandalos e otras divisiones que auia entre ellos al tiempo que se auian de poner veedores e acompañados en el dicho ofiçio, por cada uno quería seguir su voluntad atrayendo a ello sus maneras, las que entendían que mejor les venían para aver los tales ofiçios 7

Según los representantes del oficio, cada elección generaba una situación de inestabilidad institucional. Frente a esto, se solicita autorización del concejo para modificar los criterios para la designación de autoridades. En lugar de la tradicional votación en el cabildo gremial, se propone que los veedores entrantes sean designados por los salientes, a lo que el concejo accede. Este mecanismo, a las claras, impide el acceso a la veeduría a aquellos artesanos que no forman parte del núcleo dirigente de la corporación.

Sin embargo, esta disposición no logra acallar las disputas dentro del gremio. Por ello, en 1469 el concejo dispone que la elección de los veedores se lleve adelante mediante un sorteo del que solo puedan participar aquellos artesanos que no hubieran ejercido como autoridades de la corporación ${ }^{8}$. Lamentablemente, el fragmento de las actas capitulares que contiene esta disposición es en extremo escueto y no ofrece detalles sobre el contexto de su implementación. Más allá de esto, cabe destacar que en un lapso de tan solo nueve años se pasa de un mecanismo de elección que tiende a concentrar el poder gremial en manos de una pequeña elite a uno que pretende garantizar la participación igualitaria de los miembros de la corporación en la veeduría. Esto permite suponer que la conflictividad interna al gremio sería de tal magnitud que lleva al concejo a imponer un criterio de designación de autoridades radicalmente opuesto al vigente.

Martínez Martínez, Documentos relativos a los oficios artesanales en la baja Edad Media, Colección de Documentos para la Historia del Reino de Murcia XXI, [en adelante CODOM XXI]. Doc. 84, 28/6/1460, p. 95. Ver asimismo GonZÁlez ArCe, Gremios, producción artesanal y mercado, p. 33.

8 Archivo Municipal de Murcia [en adelante AMM], Actas Capitulares [en adelante AC] 1469-70, 23/6/1469, $12 \mathrm{v}$. 
Nos es imposible conocer el alcance real de esta medida dado que prácticamente no poseemos registros documentales sobre las elecciones de veedores durante la década los setenta. El único disponible data de 1478, donde encontramos que los veedores salientes nuevamente designan a los entrantes ${ }^{9}$. A pesar de no tener certezas sobre la forma de designación de autoridades en este hiato de nueve años, interesa remarcar que nuevamente se impone un criterio en extremo restrictivo, favorable a los detentadores del poder gremial.

Sin embargo, hacia el año 1480 el clima de conflictividad persiste. Como bien señalan los regidores del concejo, "entre los perayles ay devisyon cada año sobre la elección de los veedores de su oficio"10. Por ello, se vuelven a modificar los criterios de selección de autoridades con la esperanza de contener las tensiones dentro del gremio. En esta ocasión, se ensaya una fórmula novedosa. Los propios pelaires deben asentar por escrito quiénes están en condiciones de ejercer la veeduría. Una vez elaborada la lista, dos regidores se ocupan de corroborar que estos sean "abilles e suficientes para ser veedores en sus conciencias" "1. Finalmente, en vísperas del día de San Juan, los ejecutores de la ciudad proceden a elegir por sorteo a dos veedores entre los pelaires de la lista.

Es interesante destacar que la disposición concejil impide que los pelaires pobres, es decir aquellos que se desempeñan mayormente como asalariados, integren la nómina de candidatos a la veeduría. Se argumenta que su condición social los haría más propensos a incurrir en prácticas fraudulentas. Más allá de las razones esgrimidas, la exclusión de los asalariados nos permite comenzar a entrever la lógica de la lucha de clases en la disputa en torno a la designación de autoridades gremiales. ${ }^{12}$

Diez años más tarde el oficio de los pelaires aparece eligiendo a sus autoridades de forma directa, en el seno del cabildo gremial ${ }^{13}$. Desconocemos el contexto de semejante cambio a raíz de la opacidad de las fuentes. Pero el regreso a esta forma de elección es efímero, ya que en 1497 se produce una nueva alteración de los mecanismos electorales.

En ese año los regidores señalan que entre los miembros del gremio "esta cierto debate e question diziendo los unos que son agraviados de los otros del dicho oficio por quanto no los ponen en el oficio de la veeduría a ante algunos dellos se la reparten entre si" ${ }^{\prime 4}$. Este pasaje resulta esclarecedor, en tanto no solo muestra que diversas facciones se disputan la veeduría, sino que hay una que tiende a imponerse, lo que lleva a que los excluidos se manifiesten agraviados. Frente a esta situación, las autoridades municipales resuelven reimplantar el sorteo como mecanismo de elección de veedores, según había sido dispuesto en 1469 .

\footnotetext{
9 A.M.M., AC 1478-9, 24/6/1478, 9v.

10 A.M.M., AC 1479-80, 6/6/1480, 228v.

11 A.M.M., AC 1479-80, 17/6/1480, 234v.

12 Según lo apuntado por González Arce, con esta medida la veeduría quedaría consagrada a la elite gremial. GonzÁlez Arce, Gremios, producción artesanal y mercado, p. 34. Asimismo, ver Martínez MartíneZ, La industria del vestido en Murcia (siglos XIII-XV), p. 261.

13 A.M.M. AC, 1490-1, 24/6/1490, 4r.

14 A.M.M., AC, 1496-7, 6/6/1497, 135 r-v.
} 
Ahora bien, en esta ocasión son impuestas algunas restricciones adicionales que arrojan luz sobre las diferencias sociales al interior del gremio. Por un lado, en el caso de que los veedores tengan la capacidad económica suficiente para elaborar paños por cuenta propia, no podrán inspeccionar su producción, porque de lo contrario actuarían como juez y parte. De modo que los textiles de su propiedad deben ser controlados por los jueces ejecutores del concejo, quienes serán asesorados por otros oficiales del gremio. Por el otro, queda prohibido que aquel que se desenvuelva como veedor "vaya a cardar por las casas", es decir aquel que trabaje a cambio de un salario ${ }^{15}$. Así, en caso de que un pelaire pobre fuera electo veedor no podría ejercer su oficio, debiendo subsistir exclusivamente de los ingresos procedentes de la veeduría ${ }^{16}$. En este punto, es notable cómo el concejo favorece a los pelaires acaudalados a quienes se les permite continuar con su actividad económica aun cuando se desempeñan como autoridades gremiales.

Finalmente, es la intervención de la Monarquía la que logra poner fin a cuatro décadas de oscilaciones en torno a la modalidad de selección de autoridades corporativas. En 1494 los Reyes Católicos comienzan a regular la producción textil del reino con el objeto de elevar su calidad y homogeneizar a los distintos circuitos pañeros que coexisten en el territorio castellano ${ }^{17}$. Con ese objeto, se establecen unas ordenanzas generales para la producción de paños en el $1500^{18}$. Estas regulan múltiples aspectos relacionados al mundo textil, entre ellos la elección de autoridades gremiales. A partir de ese año, los gremios que intervienen en la pañería deben presentar anualmente cuatro candidatos para ejercer la veeduría ante los regidores del concejo, quienes eligen a dos para que se desempeñen en el cargo. A partir de allí no habrá cambios en el criterio de selección de autoridades por el resto del período que nos ocupa.

Hasta aquí hemos visto que la elección de autoridades gremiales produce una situación de inestabilidad dentro del oficio. Es patente que una facción del gremio trata de monopolizar la veeduría, lo que genera una gran resistencia entre aquellos excluidos. De ahí la imposibilidad de lograr que un mecanismo de designación de veedores perdure. Luego de haber realizado esta primera aproximación al conflicto, nos proponemos identificar a los pelaires que ocupan la dirección gremial. De esta manera podremos tener más precisiones sobre el grado de monopolización del cargo en cuestión, así como de la condición social de aquellos que lo detentan.

15 A.M.M., AC, 1496-7, 6/6/1497, 135 r-v. Los pelaires asalariados realizaban el cardado de los paños en la casa-taller de sus empleadores, de ahí la expresión "cardar por las casas."

16 Estos comprendían las tasas de examen, el cobro por inspeccionar los paños y las multas.

17 Gomariz Marín, Colección de documentos para la historia del Reino de Murcia XX. Documentos de los Reyes Católicos (1492-1504) [en adelante CODOM XX], doc. 132, 17/6/1494. Para un análisis pormenorizado de estas ordenanzas ver IRADIEL, Evolución de la industria textil castellana en los siglos XIII-XVI; AsEnjo GonzÁLez, "Transformación de la manufactura de paños en Castilla: las Ordenanzas Generales de 1500"; GONZÁLEZ ARCE, "La organización de la producción textil y las corporaciones gremiales".

18 CODOM XX, doc. 379, 15/9/1500. 


\section{Los veedores electos}

Hemos identificado a los veedores correspondientes a treinta de los sesenta años transcurridos entre 1450-1510, lo que puede observarse en el siguiente cuadro. Para el resto de los años no hay rastros documentales debido a que no ha sido registrada la elección en las actas concejiles. De todas maneras, la muestra es representativa.

\begin{tabular}{|l|l|}
\hline Año & Veedores \\
\hline $1450-1$ & No hay registro \\
\hline $1451-2$ & No hay registro \\
\hline $1452-3$ & No hay registro \\
\hline $1453-4$ & No hay registro \\
\hline $1454-5$ & Johan Lax y Juan Roldán ${ }^{19}$ \\
\hline $1455-6$ & No hay actas \\
\hline $1456-7$ & No hay registro \\
\hline $1457-8$ & Pedro Navarro y Diego García de Alcaraz ${ }^{20}$ \\
\hline $1458-9$ & No hay registro \\
\hline $1459-60$ & No hay registro \\
\hline $1460-1$ & Juan Roldán y Ramón Perellón ${ }^{21}$ \\
\hline $1461-2$ & No hay registro \\
\hline $1462-3$ & No hay registro \\
\hline $1463-4$ & No hay registro \\
\hline $1464-5$ & Rodrigo de Albaçete e Ferrand de Alcaraz e Juan Lax e Martín Pujol e Pedro Navarro ${ }^{22}$ \\
\hline $1465-6$ & Juan Sánchez de Munuera y Juan Guerao ${ }^{23}$ \\
\hline $1466-7$ & No hay registro \\
\hline $1467-8$ & Ferrand Martínez de Alcaraz y Alonso de Molina ${ }^{24}$ \\
\hline $1468-9$ & No hay registro \\
\hline $1469-70$ & No hay registro \\
\hline $1470-71$ & No hay registro \\
\hline $1471-72$ & No hay registro \\
\hline $1472-73$ & Rodrigo de Albacete ${ }^{25}$ \\
\hline
\end{tabular}

19 CODOM XXI, doc. $73,8 / 2 / 1455$.

20 CODOM XXI, doc. $79,7 / 3 / 1458$.

21 CODOM XXI, doc. 84, 28/6/1460.

22 En este caso, los cuatro pelaires en cuestión aparecen hablando en nombre del oficio ante el concejo, probablemente dos de estos habrían sido veedores.

23 CODOM XXI, doc. 97, 26/10/1465.

24 CODOM XXI, doc. 110, 26/9/1467. 


\begin{tabular}{|c|c|}
\hline Año & Veedores \\
\hline $1473-4$ & No hay registro \\
\hline $1474-5$ & No hay registro \\
\hline $1476-7$ & No hay registro \\
\hline $1477-78$ & Alfonso Roldán y Rodrigo de Albacete ${ }^{26}$ \\
\hline $1478-79$ & Bartolomé de Albacete y Garcí Ruiz ${ }^{27}$ \\
\hline $1479-80$ & No hay registro \\
\hline $1480-81$ & Juan Roldán y Luis Baeza ${ }^{28}$ \\
\hline $1481-82$ & Rodrigo de Albaçete e Alfonso Roldan ${ }^{29}$ \\
\hline $1482-83$ & No hay registro \\
\hline $1483-84$ & No hay registro \\
\hline $1484-5$ & No hay registro \\
\hline $1485-6$ & Martín Pujol y Juan López de Bonilla ${ }^{30}$ \\
\hline $1486-7$ & No hay registro \\
\hline $1487-8$ & No hay registro \\
\hline $1488-9$ & Rodrigo de Albacete ${ }^{31}$ \\
\hline $1489-90$ & Pedro de Albacete 32 \\
\hline $1490-1$ & No hay registro \\
\hline $1491-2$ & Lorenzo Serrano y Juan de Castro ${ }^{33}$ \\
\hline $1492-3$ & Alfonso Roldan y Lorenzo de Castro ${ }^{34}$ \\
\hline $1493-4$ & Juan Roldan y Garci Ruiz ${ }^{35}$ \\
\hline $1494-5$ & Diego de Bonilla y Alfonso Roldán ${ }^{36}$ \\
\hline $1495-6$ & No hay registro \\
\hline $1496-7$ & No hay registro \\
\hline $1497-8$ & Ginés Belloq y Alfonso de VIllalobos ${ }^{37}$ \\
\hline
\end{tabular}

25 Aparece asesorando al conejo en cuestiones vinculadas a la calidad del tintado de los paños, lo cual era algo típicamente realizado por los veedores de la pelairía. A.M.M. AC 1472-3, 6/10/1472, 61v.

26 A.M.M. AC 1478-9, 24/6/1478, 9v. Alfonso Roldán y Rodrigo Albacete aparecen nombrando a sus sucesores.

27 A.M.M. AC 1478-9, 24/6/1478, 9v.

28 Martínez Martínez, La industria del vestido en Murcia (siglos XIII-XV), p.258.

29 A.M.M. AC 1481-2, 23/4/1482, 235v.

30 CODOM XXI, doc. 153, 9/7/1495.

31 CODOM XXI, doc. 164, 27/10/1489. Declara haber sido veedor durante el período 1488-9.

32 CODOM XXI, doc. 164, 27/10/1489.

33 Martínez Martínez, La industria del vestido en Murcia (siglos XIII-XV), p.258.

4 A.M.M. AC 1492-3, 22/6/1492, 4r.

Martínez Martínez, La industria del vestido en Murcia (siglos XIII-XV), p.258.

A.M.M. AC, 1494-5, 24/6/1494, 7r.

A.M.M. AC, 1497-8, 24/6/1497, 4v. 
LAS DISPUTAS EN TORNO A LA DESIGNACIÓN DE VEEDORES EN EL GREMIO DE LOS PELAIRES...

\begin{tabular}{|l|l|}
\hline Año & Veedores \\
\hline $1498-9$ & Jaime Tornel y Pedro Claverol ${ }^{18}$ \\
\hline $1499-00$ & No hay registro \\
\hline $1500-01$ & Gines Serrano y Bartolomé de Servelo. Juan Roldán y Garcí Ruiz \\
\hline $1501-02$ & Diego de Bonilla y Lorenzo Serrano. Juan Roldán y Juan de Castro \\
\hline $1502-3$ & Juan Roldán y Juan de Castro ${ }^{41}$ \\
\hline $1503-4$ & Alfonso Roldán y Lorenzo Serrano. Bartolomé de Albacete y Guillen Serrano ${ }^{42}$ \\
\hline $1504-5$ & Juan Roldán “el viejo" y Juan de Castro ${ }^{43}$ \\
\hline $1505-6$ & Bartolomé Albacete y Garcí Ruiz. Alfonso Roldán y Juan Guerao ${ }^{44}$ \\
\hline $1506-7$ & Juan Guerao y Ginés Roldán. Alfonso Roldán ${ }^{45}$ \\
\hline $1507-8$ & Juan Roldán “el viejo" y Jaime Tornel. Pedro de Albacete y Lorenzo Serrano ${ }^{46}$ \\
\hline $1508-9$ & No hay registro \\
\hline $1509-10$ & Jaime Tornel y Lopez Ruiz. Bartolomé de Albacete y Ginés Serrano ${ }^{47}$ \\
\hline $1510-11$ & Alfonso Roldán y Martín Ruyz. Bartolomé de Albacete y Juan Ruyz ${ }^{48}$ \\
\hline
\end{tabular}

A primera vista, es posible observar que determinadas familias tienden a reiterarse en el ejercicio de la veeduría, mientras que otras aparecen en el cargo de forma esporádica. Si ordenamos los datos en función de la cantidad de mandatos que corresponden a cada familia obtenemos el siguiente resultado:

\begin{tabular}{|l|l|}
\hline Familia & Cantidad de mandatos \\
\hline Roldán & 13 \\
\hline Albacete & 12 \\
\hline Serrano & 7 \\
\hline de Castro & 5 \\
\hline Ruiz & 5 \\
\hline
\end{tabular}

38 A.M.M. AC, 1498-9, 24/6/1498, 2v.

39 A partir de este año, el gremio debe postular a cuatro candidatos ante las autoridades concejiles, quienes elegirán a dos para desempeñarse como veedores. Para la mayor parte de los casos ha sido registrada la terna entera, como se refleja en el cuadro. Los veedores electos por el concejo figuran en negrita. A.M.M. AC, $1500-1,4 / 5 / 1501,165 \mathrm{v}$.

40 A.M.M. AC, 1501-2, 26/6/1501, 5r.

41 A.M.M. AC, 1502-3, 24/6/1502, 6r.

42 A.M.M. AC, 1503-4, 1/7/1503, 12 r.

43 A.M.M. AC, 1504-5, 25/6/1504, 5r.

44 A.M.M. AC, 1505-6, 24/6/1505, 4v.

45 A.M.M. AC, 1506-7, 4/7/1506, 8v.

46 A.M.M. AC, 1507-8, 26/7/1507, 6v

47 A.M.M. AC, 1509-10, 26/6/1509, 8v.

48 A.M.M. AC, 1510-1. 24/6/1510, 9r. 


\begin{tabular}{|l|l|}
\hline Familia & Cantidad de mandatos \\
\hline Alcaraz & 3 \\
\hline Bonilla & 3 \\
\hline Tornel & 3 \\
\hline Guerao & 2 \\
\hline Lax & 2 \\
\hline Navarro & 2 \\
\hline Pujol & 2 \\
\hline Baeza & 1 \\
\hline Belloq & 1 \\
\hline Claverol & 1 \\
\hline Molina & 1 \\
\hline Perellón & 1 \\
\hline Sánchez de Munuera & 1 \\
\hline Servelo & 1 \\
\hline Villalobos & 1 \\
\hline
\end{tabular}

Las autoridades gremiales del período estudiado proceden de un total de veinte familias. Dos de ellas, Roldán y Albacete, son las que ocupan de forma preponderante la dirección del gremio, aportando entre las dos a veinticinco de los sesenta y siete veedores identificados para el período. En términos porcentuales, de estas familias proceden un $37,31 \%$ de las autoridades electas. Estas son secundadas por los Serrano, Ruiz y de Castro, participando los primeros siete veces en la dirección del gremio y los últimos en cinco ocasiones cada uno. Si tomamos a estas cinco familias en su conjunto, encontramos que aportan al 62,69\% de las autoridades gremiales.

El 37,31\% restante proviene de quince familias. Estas ocupan la veeduría de forma ocasional. Siete lo hacen entre dos y tres veces, y ocho solo una vez. Tomadas en su conjunto, estas familias aportan veinticinco veedores, la misma cantidad que los Roldán y Albacete sumados. De lo expuesto queda claro que existe una minoría que tiende a monopolizar la dirección del gremio, más allá de las constantes alteraciones en los mecanismos para designar autoridades.

Llegado a este punto, resulta necesario comprobar si la elite dirigente del gremio pelaire forma parte a la vez de su elite económica. Por vía directa, solo nos es posible estimar el patrimonio de la familia Albacete. A partir de la documentación notarial murciana conocemos la cuantía de la dote correspondiente de Isabel Albacete, hija del pelaire Bartolomé Albacete, quien contrae matrimonio en 1492. Esta consta de mil reales castellanos en ropas, joyas y preseas de la casa y otros veinte mil maravedíes en paños y 
dinero $^{49}$. Esta suma, de por sí elevada, es solo una fracción de la fortuna familiar, lo que nos da la pauta de que el patrimonio de los Albacete es propio de pecheros acaudalados. Lamentablemente, el registro documental no permite conocer de manera precisa el estado patrimonial del resto de las familias que conforman a la elite dirigente del gremio. Sin embargo, es posible conocer la pertenencia social de estas por otras vías.

En 1496, una veintena de pelaires suscriben una obligación ante el concejo para monopolizar la venta de paños en Murcia ${ }^{50}$. Los firmantes componen la elite empresarial del gremio. Estos tienen la capacidad económica para comprometerse a elaborar paños con el fin de abastecer íntegramente a una ciudad de entre nueve mil y diez mil habitantes ${ }^{51}$. Para ello deben adquirir la materia prima y entregarla para que sea elaborada por los distintos artesanos que componen los numerosos eslabones del proceso productivo textil, los cuales trabajan por encargo. Los empresarios pelaires se encuentran abocados a tareas de gestión y coordinación del proceso productivo, así como a la comercialización del producto acabado. Los Roldán, Serrano, Ruiz y de Castro se encuentran entre los firmantes de esta obligación. Como es de esperarse, los Albacete también participan de este acuerdo. En función de lo visto, podemos afirmar que las familias de pelaires que controlan la corporación pertenecen a la elite económica del gremio. Resta determinar la condición social de las familias que acceden a la dirección gremial de forma esporádica. Esto nos permitirá avanzar en la caracterización del conflicto que nos ocupa.

\section{Los veedores ocasionales}

En los diez años transcurridos entre 1450 y 1460, sobre seis veedores identificados, cuatro corresponden a familias poco representadas: Juan Lax (1454-5), Pedro Navarro (1457-8), Diego García de Alcaraz (1457-8) y Ramón Perellón (1460-1). En esta década prima la elección de los veedores por parte de la asamblea gremial. Ahora bien, los descendientes de Pedro Navarro y Diego García de Alcaraz participan de la obligación de 1496, lo que permite estimar que, al menos hacia fin de siglo, ambas familias forman parte del sector acaudalado del gremio.

Por otra parte, resulta interesante analizar las medidas concretas llevadas por estos pelaires durante el ejercicio de la veeduría. Alcaraz y Navarro solicitan a las autoridades municipales la imposición de salarios más bajos a tejedores y urdideras. Estos artesanos escapan a la jurisdicción del gremio pelaire, aunque trabajan al servicio de los empresarios de esta corporación ${ }^{52}$. Esta medida redunda en un aumento de la tasa

\footnotetext{
49 Archivo Histórico Provincial de Murcia, Fondo Notarial de Murcia, Protocolo 433, 111 r-v.

50 CODOM XXI, doc. 175. 17/12/1496. Hemos estudiado los pormenores de este acuerdo en FAzZINI, "La construcción de la hegemonía pelaire en la protoindustria textil murciana". Del mismo modo, ver Martínez Martínez, La industria del vestido en Murcia (siglos XIII-XV), p. 137-142 y GonzÁlez ArCe, Gremios, producción artesanal y mercado, p. 180.

51 Molina Molina, "Datos sobre sociodemografía murciana a fines de la edad media (1475-1515)".

52 CODOM XXI, doc. 79. 7/3/1458
} 
de explotación de los asalariados. En el caso de Ramón Perellón, este es uno de los artífices del primer intento de restringir la elección de representantes a gremiales a los veedores salientes que hemos analizado.

Así, podemos afirmar que, al margen de su situación patrimonial, las políticas impulsadas por Navarro, Alcaraz y Perellón están en sintonía con el interés de la elite dirigente del gremio. Con respecto a Juan Lax, su figura se mantiene como una incógnita.

Durante la década de 1460, los veedores provenientes de familias con pocas participaciones en el cargo son Ferrand Martínez de Alcaraz (1464-5 y 1467-8), Juan Lax (1464-5), Pedro Navarro (1464-5), Martín Pujol (1464-5), Juan Sánchez de Munuera (1465-6), Juan Guerao (1465-6) y Alonso de Molina (1467-8). Ya hemos analizado a los tres primeros. Con respecto a Martín Pujol, no conocemos su nivel de riqueza ni tampoco poseemos demasiados detalles sobre su labor como autoridad gremial. En el caso de Juan Guerao, este es uno de los pelaires firmantes de la obligación de 1496 para abastecer de paños a la ciudad; asimismo, participa Pedro Molina, probablemente hijo o sobrino de Alonso de Molina. Resulta más complejo estimar la condición social de Juan Sánchez de Munuera. Solo sabemos que durante su mandato como veedor debió afrontar con sus bienes, en conjunto con Juan Guerao, las deudas de un pelaire que se había fugado de la ciudad sin haber presentado un fiador ${ }^{53}$. Esto permite intuir que, de mínimas, este pelaire no se corresponde con el sector menos pudiente de la corporación.

Por otra parte, en 1467 Alcaraz y Molina impulsan ante el concejo de la ciudad una medida clave en cuanto a su potencial para construir el poderío económico de la elite pelaire: la prohibición a los tejedores de comprar hilaza. De esta forma, se logra impedir el trabajo independiente de los artesanos pertenecientes a uno de los oficios centrales del ciclo textil, quienes quedan obligados a trabajar por encargo de los empresarios pelaires ${ }^{54}$. Para los años transcurridos entre 1470 y 1480 no contamos con veedores provenientes de familias con poco peso en la dirección del gremio, lo que sí ocurre en la década siguiente, cuando encontramos a Luis Baeza (1480-81), Martín Pujol (1485-6) y Juan López de Bonilla (1485-6).

Como hemos explicado, en la década de 1480 los veedores se eligen a partir de un sorteo que excluye a los pelaires pobres. Por ende, podemos afirmar que las autoridades nuevas del período, por lo menos pertenecen al estrato medio de la corporación. En el caso de Juan López de Bonilla, distintos miembros de su familia aparecen firmando la obligación de 1496, lo que permite aseverar su pertenencia al sector acaudalado.

En la década de 1490, Diego de Bonilla (1494-5), Ginés Belloq (1497-8), Alfonso de Villalobos (1497-8), Jaime Tornel (1498-9) y Pedro Claverol (1498-9) ofician como autoridades gremiales. Todos participan de la obligación de 1496. Finalmente, entre 1500 y 1510, contamos con dos mandatos de Jaime Tornel, uno de Diego de Bonilla,

\footnotetext{
53 A.M.M. AC, 1465-6, 26/10/1465, 48 r-v.

54 CODOM XXI, doc.110, 26/9/1467. Debemos aclarar que antes de esta medida los tejedores combinaban el trabajo por encargo con la elaboración de textiles de manera independiente. Ver FAzZinI, "La construcción de la hegemonía pelaire en la protoindustria textil murciana".
} 
y aparece ejerciendo la veeduría por primera vez Bartolomé Servelo, quien a su vez firma el compromiso de 1496 en carácter de empresario de paños.

En función de lo expuesto, podemos afirmar que el grueso de los pelaires que ofician como veedores de forma esporádica pertenece a la elite económica del gremio. Es decir que no existen diferencias desde el punto de vista sociológico entre estos y los miembros de las familias que conforman a la dirección de la corporación. En este sentido, la ligera alternancia en el ejercicio de la veeduría se produce mayormente dentro del mismo sector social. Esto demuestra cabalmente cuál es el límite de la utilización de mecanismos menos restrictivos a la participación como el sorteo: la incorporación fugaz como veedores de pelaires empresarios que no forman parte de la conducción estable del gremio.

A la vez, debemos destacar que existe una continuidad en las prácticas de las autoridades corporativas durante el período estudiado. Independientemente de quiénes sean, se observa una lógica que apunta a garantizar el mismo interés estratégico, la acumulación por parte del núcleo de empresarios pelaires. De hecho, algunos de los veedores provenientes de familias con menor cantidad de participaciones en el cargo impulsan disposiciones fundamentales para la construcción del poder institucional y económico de la elite pelaire, como hemos visto en el caso de Lax, Alcaraz, Navarro y Molina.

En este punto, debemos preguntarnos si los pelaires con pocas participaciones en la veeduría gremial son los responsables de la inestabilidad política generada en el momento de elegir a las autoridades. En otras palabras, se plantea como interrogante si estos operan como una facción excluida que disputa la dirección política del gremio con las familias más poderosas.

Para evaluar esta posibilidad, resulta útil prestar atención a los criterios utilizados para designar a los veedores ocasionales. De las veinticinco veces en que pelaires de este grupo son electos como autoridades gremiales, un tercio es gracias a la designación por parte de los veedores salientes, dispositivo de preservación de la elite por excelencia. En diez ocasiones, los veedores son designados por la asamblea gremial ${ }^{55}$. Este mecanismo también posee una fuerte incidencia de las familias más poderosas del gremio ${ }^{56}$. Las siete elecciones restantes en las que se ven favorecidos los pelaires ajenos a la elite dirigente del gremio se realizan mediante suertes. En tres de ellas, previamente la asamblea gremial debe confeccionar una lista con los pelaires aptos para participar del sorteo. No sería extraño que la elite dirigente influyera en la elaboración de la nómina de veedores potenciales. En las otras cuatro se trata de un sorteo en términos puros.

Así, es posible afirmar que las familias más poderosas inciden en mayor o menor medida en el grueso de las elecciones en las que resultan seleccionados pelaires provenientes de

\footnotetext{
55 En cinco de esas ocasiones, los veedores son electos por la asamblea para conformar la terna que se presenta a las autoridades concejiles, quienes están encargadas de la selección final.

56 De hecho, veintiséis de los cuarenta y dos veedores de la elite dirigente del gremio acceden al cargo gracias a la elección directa en el seno del cabildo.
} 
familias con poco peso institucional. Por ende, es válido preguntarse por qué razones el núcleo dirigente de la corporación admite a estos pelaires en la veeduría.

Una posibilidad es que la presión de estos por participar de la dirección del gremio sea tal que logre torcer el brazo de la facción que controla al aparato corporativo. No obstante, es más plausible que la alternancia haya obedecido a una lógica menos traumática. Sin negar la presencia de algún tipo de conflicto, podemos suponer que la rotación en el cargo entre pelaires pertenecientes a la elite económica del gremio no contradice necesariamente al interés de la dirección de la corporación.

Por el contrario, esta alternancia acotada probablemente haya obedecido a un proceso de recambio lógico mediante el cual los miembros de las familias que dirigen al gremio abren la participación hacia otros pelaires, quizás ante la imposibilidad concreta de disponer de agentes propios en determinados años, o bien como gesto hacia el resto de la corporación con el objeto de afianzarse en la dirección gremial. Lamentablemente, la opacidad de la documentación no nos permite abandonar el terreno especulativo.

De cualquier forma, los posibles roces al interior de la elite económica del gremio no bastan para explicar el nivel de inestabilidad institucional al momento de la designación de autoridades. Por ello, a continuación nos proponemos explorar la dinámica del conflicto entre la dirección del gremio y los asalariados de la corporación.

\section{Los humillados y ofendidos}

Dentro del gremio que nos ocupa existen tres grupos de artesanos asalariados subordinados a la elite de pelaires acaudalados. En primer lugar, los cardadores de lana, quienes se encargan de preparar la materia prima para ser hilada, lo que constituye una de las primeras fases del ciclo textil. En segundo lugar, los cardadores de paños. Estos se encuentran abocados a una de las actividades que componen al oficio de la pelairía, justamente el cardado ${ }^{57}$. Por último, los tundidores, artesanos calificados cuya tarea consiste en igualar los paños luego del cardado, cortando los pelos sobrantes para dotarlos de mayor brillo.

Estos asalariados se encuentran excluidos de plano del acceso al cargo de veedor. Sobre los tundidores y cardadores de lana pesa una segregación en términos institucionales, de manera que se ven impedidos de participar de la asamblea gremial, de la redacción de ordenanzas, y, desde ya, de la elección de autoridades ${ }^{58}$. Con respecto a los cardadores de paños, si bien son miembros de pleno derecho desde el punto de vista institucional, hemos visto que no logran imponerse como autoridades gremiales.

Ahora bien, ¿son estos trabajadores asalariados los protagonistas de los conflictos en torno a las elecciones de veedores? El silencio de las fuentes disponibles en este sentido solo permite realizar algunos comentarios hipotéticos. En primer lugar, podemos

\footnotetext{
57 Ver nota 2 para mayor detalle sobre estas actividades.

58 GonzÁlez Arce, Gremios, producción artesanal y mercado, p. 196.
} 
afirmar que estos artesanos se resienten con especial animosidad del monopolio de la veeduría por parte del núcleo dirigente del gremio. Hemos señalado que los pelaires que ofician como autoridades gremiales de forma ocasional comparten el mismo interés económico y social con las familias que manejan la corporación. Por el contrario, entre estas últimas y los artesanos asalariados existe un antagonismo evidente.

Esto se hace patente en el hecho de que el andamiaje institucional del gremio, en manos de su elite dirigente, deviene en una herramienta que coadyuva al sometimiento de los asalariados. Si bien estos trabajadores dependen materialmente de los pelaires acaudalados debido a su incapacidad para elaborar paños por cuenta propia, los veedores de la corporación están facultados para regular sus salarios, así como para pautar las características fundamentales de su proceso de trabajo ${ }^{59}$. En otras palabras, los veedores del gremio actúan como garantes de la relación de explotación. Por ello el monopolio del cargo resulta particularmente gravoso para los artesanos sometidos.

De los tres grupos de asalariados, solo los tundidores aparecen confrontando abiertamente con los dirigentes del gremio en la documentación. En 1465, estos rechazan someterse a la jurisdicción de los veedores de la pelairía, así como otorgarles fianzas ${ }^{60}$. Alegan que su oficio difiere del de los pelaires, por lo que deberían poseer una corporación propia. Pero las pretensiones de los tundidores no llegan a buen puerto, en tanto el concejo afirma la autoridad de los veedores de la pelairía sobre estos.

Luego de treinta años volvemos a encontrar referencias documentales a este conflicto. En esta ocasión los tundidores poseen una mayor capacidad de presión sobre el concejo, debido a que en 1494 una pragmática de los Reyes Católicos torna obligatorio al tundido para todos los paños que se elaboren en el reino ${ }^{61}$. Antes era una operación optativa que solo se practicaba en los mejores paños.

Es en este contexto cuando algunos maestros del oficio se presentan ante el concejo para manifestase agraviados por los pelaires. Señalan que

\footnotetext{
59 Por ejemplo, en 1466 las autoridades gremiales defienden ante el concejo la potestad para en exclusivo "oyr e judgar e determinar las cosas que sean entre los dichos perayles e sus moços e criados las dichas cosas que le son e ofiçian devydas de sus jornales e adobos de paños e pilateryas [abatanado] e cardaje a la percha fasta en la costa que los dichos aparejos valieren", frente a la intromisión de los jueces ejecutores de la ciudad. El concejo encuentra razonable la demanda. A.M.M, A.C, 1465-6, 18/5/1466, 98r-v. Asimismo, en 1486 los representantes de la pelairía reglamentan de forma minuciosa las características que deben tener las herramientas con las que trabajan los cardadores de lanas, prohibiendo la utilización de cardas de hierro para evitar daños en la materia prima. Cabe aclarar que estos artesanos se encuentran en posesión de sus instrumentos de trabajo. De ahí que sea necesaria la intervención institucional para que estos sean adaptados a las necesidades de la acumulación pelaire. CODOM XXI, doc.140, 19/11/1486. 60 Los veedores gremiales debían recibir una suma dineraria de cada miembro del oficio en concepto de fianza, que servía como reaseguro en caso que estos cometieran daños sobre las materias primas que recibían para elaborar. En el caso de que un artesano no las hubiese entregado y luego se presentara insolvente, serían los veedores del gremio los que deberían responder con su patrimonio ante alguna falta, como hemos observado con los veedores Sánchez de Munuera y Guerao.

${ }^{61}$ CODOM XX, doc. 132, 17/6/1494.
} 
teniendo los ofiçios de la peraylia e tundir su pendon e capilla, en lo qual nuestro ofiçio contribuye e los perayles entran en cabildo e fazen sus hordenanças, [...] e sacan vehedores syn nos llamar e fazxer mençion de nosotros en ninguna cosa. ${ }^{62}$

Frente a esta situación, debido a que contribuyen monetariamente al sostenimiento del gremio, reclaman al concejo que los pelaires los "llamen a su cabildo e entremos con ellos en el dicho ofiçio de la veedoria e anden por su rueda o nos saquen debaxo de su pendon, ca nosotros faremos nuestro pendon e faremos en el ofiçio lo que cumpliere"63. De esta manera, plantean dos alternativas a las autoridades concejiles: el acceso a la veeduría, o bien la autorización para formar un gremio propio, independiente con respecto a la pelairía.

En esta ocasión, el concejo encuentra razonable la demanda de los maestros tundidores, por lo que insta a los pelaires a que los admitan en la veeduría. De lo contrario, quedarán autorizados a conformar un gremio separado ${ }^{64}$. Esto provoca la protesta de las autoridades pelaires, que lejos de ceder, alegan que las diferencias de calificación entre ambos oficios justifican la subordinación institucional de los tundidores ${ }^{65}$. No obstante, el concejo se mantiene firme en su resolución y, ante la negativa de los pelaires, autoriza a los tundidores para que elaboren ordenanzas propias ${ }^{66}$, las cuales son presentadas días más tarde, quedando así constituida la nueva corporación ${ }^{67}$.

Es destacable que los dirigentes de la pelairía prefieren perder la jurisdicción sobre los tundidores antes que compartir el poder gremial con artesanos ajenos a la elite económica de la corporación. En este sentido, si bien la escisión de los tundidores implica una merma en el poder del empresariado pelaire, podemos suponer que este es el menor entre dos males. Sobre todo teniendo en cuenta que, aun institucionalmente independientes, los tundidores continúan subordinados en términos materiales.

Con respecto a los cardadores de paños y lanas no hay evidencia directa sobre la confrontación con los veedores pelaires. Ahora bien, a comienzos de la centuria del quinientos estos se han escindido del gremio de la pelairía. Sin poder conocer el proceso que desemboca en la conformación de corporaciones independientes, podemos suponer

62 CODOM XXI, doc. 177, 31/7/1498, p.203. Ver también GonZÁleZ ArCE, Gremios, producción artesanal y mercado, pp. 54-56.

63 CODOM XXI, doc. 177, 31/7/1498, pp. 203-4.

64 A.M.M. AC, 1498-9 31/7/1498, 30r.

65 CODOM XXI, doc. 178, 11/8/1498.

66 A.M.M. AC, 1498-9, 14/8/1498, 36r.

67 CODOM XXI, doc. 179, 21/8/1498. Es interesante que tras la independencia del gremio de los pelaires, los tundidores no solo pueden elegir libremente a sus autoridades, sino que también adquieren la potestad para elaborar una insignia propia y participar de forma autónoma en las procesiones urbanas, particularmente la del Corpus Christi. Se puede pensar que esto haya operado como un estímulo adicional para la formación de una corporación propia, sobre todo teniendo en cuenta que los lugares ocupados por las corporaciones en la procesión son disputados por los distintos oficios, puesto que constituyen una marca de reconocimiento social. Ver MarTínez Martínez, "El poder representado y la representación del poder", pp. 218-228. 
un camino análogo al de los tundidores. Es decir que la separación aparezca como la alternativa viable para escapar al control de la elite pelaire, ante la imposibilidad de acceder a los espacios de poder dentro del gremio ${ }^{68}$.

Ambas escisiones implican una merma en la capacidad de control y supervisión del proceso productivo por parte del empresariado pelaire. Esto es particularmente notorio con la creación del gremio de cardadores de lana, cuyas autoridades quedan facultadas para ingresar en los talleres de los pelaires para inspeccionar la labor de sus mozos y criados en la preparación de la lana antes de ser hilada ${ }^{69}$. Esto genera la protesta enérgica de los miembros del oficio de la pelairía, aunque el concejo se mantiene firme en su decisión de dotar a los cardadores de jurisdicción sobre los talleres donde se carde lana ${ }^{70}$.

Finalmente, un año después de la independencia de los cardadores de lana encontramos evidencia sobre la separación de los cardadores de paños. Este es el caso más llamativo, dado que estos artesanos son en esencia pelaires. Tundidores y cardadores de lana son artesanos cuyos oficios difieren de la pelairía, lo que sustenta la constitución de una corporación autónoma. Por el contrario, la diferencia entre cardadores de paños y pelaires no obedece a un criterio técnico-laboral, sino social. Es decir que si bien los primeros poseen el conjunto de los conocimientos propios del oficio de la pelairía, carecen de la capacidad económica para desempeñarse de forma autónoma, de manera que se ven obligados a vender su fuerza de trabajo. En este sentido, es la condición de trabajadores asalariados, y no la del ejercicio de un métier distinto al del pelaire, el fundamento para la formación del gremio de los cardadores de paños.

Como es de esperarse, la separación de los oficios trae aparejada nuevos conflictos. En este caso, encontramos que producto de la indistinción técnica entre cardadores de paños y pelaires, las autoridades de ambas corporaciones se disputan la jurisdicción sobre cinco artesanos que, si bien han sido examinados como pelaires, "van a cardar por las casas alquilados", es decir que venden su fuerza de trabajo ${ }^{71}$. Finalmente, el concejo determina que los artesanos en cuestión queden bajo la órbita del gremio de los cardadores de paños. La separación de estos tres grupos de artesanos permite estimar la conflictividad hacia el interior del gremio pelaire durante la segunda mitad del siglo XV. Hemos visto cómo los tundidores presionan para acceder a este cargo, lo que culmina en su constitución

\footnotetext{
68 Al igual que con los tundidores, la independencia de los cardadores de lana es posible gracias a la regulación productiva emanada por la corona. En este caso, las ordenanzas generales de paños del 1500 refuerzan el control sobre las actividades preliminares del proceso productivo, lo que fortalece la posición de los cardadores de lana frente a los pelaires. Esto permitirá la independencia de dichos artesanos. CODOM XX doc. 379, 15/9/1500. Asimismo, ver Martínez Martínez, La industria del vestido en Murcia (siglos XIII-XV), p. 33 y GonZÁlez Arce, Gremios, producción artesanal y mercado, p. 56.

69 A.M.M., A.C. 1501-2, 6/7/1501, 10r, 15r-v

70 A.M.M., A.C. 1501-2, 13/7/1501, 16v-17r. Para manifestar el agravio se presentan Juan Roldan, Pero López de Bonilla, Juan de Castro y Lorenzo Serrano. Este último es el veedor, mientas que Juan Roldán y Juan de Castro habían sido ternados, pero no electos por el concejo para ejercer el cargo. En este sentido, independientemente de quién ejerza como veedor, podemos observar que los pelaires actúan en bloque en defensa de su interés económico y social.

71 A.M.M., A.C 1502-3 13/8/1502 52v-53r
} 
como gremio independiente. Es posible especular con que cardadores de lanas y cardadores de paños asimismo hayan bregado por nombrar autoridades de la corporación. El grado de peligro que suponía para los empresarios pelaires el acceso a la veeduría por parte de los asalariados de la corporación se hace patente tras las escisiones analizadas. La formación de gremios independientes por parte de estos artesanos logra romper con el control unilateral que ejercía la elite pelaire sobre el proceso productivo y los niveles salariales internos a la corporación. Estas son las prerrogativas que fueron celosamente defendidas durante el siglo $\mathrm{XV}$, cuando la veeduría del gremio era monopolizada por una pequeña elite.

\section{Conflictos intragremiales en Castilla y Aragón}

En este punto, en virtud de la poca documentación disponible para el caso analizado, resulta útil el recurso a la comparación con la conflictividad interna de otras corporaciones de artesanos castellanas y aragonesas. Esto nos permitirá juzgar la verosimilitud de lo que hemos planteado para el caso que nos ocupa. Para ello recurriremos a la historiografía que, si bien no ha analizado detenidamente el problema de las disputas en torno a la selección de autoridades gremiales, presenta datos que son útiles a efectos de realizar una contraposición con nuestros resultados.

En primer lugar, debemos destacar que el control de los gremios por unas pocas familias acaudaladas, como se da en el caso que estudiamos, lejos de ser una excentricidad, pareciera más bien ser la regla, como afirman de manera general para el contexto europeo bajomedieval Farr y Córdoba de la Llave ${ }^{72}$. Esto es particularmente notorio entre los oficios textiles. En Segovia, a comienzos del siglo XVI, el gremio de los tintoreros se encuentra manejado por sus miembros acaudalados, como bien señala González $\mathrm{Arce}^{73}$. Lo mismo sucede en Barcelona a comienzos del siglo XIV, donde las corporaciones de pelaires, tintoreros y tejedores se encuentran dominadas por una minoría que se mantiene en el poder mediante la designación de las autoridades salientes por las entrantes ${ }^{74}$. Este método, como hemos visto, es utilizado en el caso murciano. En Valencia, a mediados del siglo XV, los mayorales del oficio de los tejedores de seda provienen de una pequeña elite ${ }^{75}$. También el moderno Arts des Velluters (tejedores de terciopelo) de la dicha ciudad es controlado por unos pocos maestros acaudalados desde el momento de su constitución en $1479^{76}$, al igual que los gremios de manteros de

\footnotetext{
72 FARr, Artisans in Europe, 1300-1914, pp. 159-64; Córdoba de la Llave, Los oficios medievales, p. 185.

73 GonzÁlez Arce, "Los gremios contra la construcción del libre mercado", p. 27. Este caso es particularmente interesante puesto que, como analizar el autor, la elite gremial se encuentra compuesta por mercaderes que tienen bajo su control a los tintoreros locales.

74 Riera i Melis, "La aparición de las corporaciones de oficio en Cataluña (1200-1350)", p. 308

75 Navarro Espinach, El Despegue de La Industria Sedera En La Valencia Del Siglo XV, p. 54.

76 García CÁrcel, Las Germanías de Valencia, 31; NaVArro Espinach, El Despegue de La Industria Sedera En La Valencia Del Siglo XV, p. 140.
} 
Mallorca $^{77} \mathrm{y}$ de boneteros de Córdoba en ese mismo período ${ }^{78}$. Por fuera de los oficios pertenecientes a la industria del vestido, es notoria la monopolización de la dirección corporativa por parte de las familias acaudaladas en los gremios de la construcción, como se observa entre los albañiles murcianos ${ }^{79}$.

Igualmente, han sido documentadas disputas por la dirección de diversas corporaciones. A comienzos del siglo XVI, Palencia atestigua un pleito entre los tejedores agrupados en la cofradía de Santa María del Ángel y aquellos que se encuentran por fuera de esta, excluidos de la elección de veedores.$^{80}$ Del mismo modo, tanto en Valencia como en Mallorca es posible encontrar disputas en torno a la elección de autoridades dentro del gremio de los pelaires. Al igual que lo que hemos planteado para Murcia, en estos casos la polarización social entre los artesanos resulta determinante ${ }^{81}$. El caso valenciano es sugestivo, dado que la diferenciación económica se cristaliza en la formación de dos cofradías religiosas distintas, la de mestres peraires, que agrupa a los artesanos económicamente más poderosos, y la de macips peraires, que aglutina a los asalariados. En este sentido, si bien todos comparten una misma organización corporativa, la fractura social del gremio se expresa en dos advocaciones distintas ${ }^{82}$. A comienzos del siglo XV ambas fracciones intentan imponer a sus miembros como veedores de la corporación ${ }^{83}$. A la vez, entre los pelaires de Mallorca se ha documentado un conflicto similar a mediados del siglo XVII. En este caso, los miembros más acaudalados de la corporación buscan alterar los criterios de selección de autoridades para evitar la participación de los asalariados en la veeduría del gremio, práctica que también hemos visto para Murcia. Sin embargo, gracias a la mediación de las autoridades locales, se obtiene una solución de compromiso, de modo que los artesanos menos afortunados habrían logrado alguna participación en la dirección gremial ${ }^{84}$.

Entre los artesanos de la industria de la seda valencianos la designación de autoridades es igual de conflictiva. En la coyuntura inmediatamente anterior al estallido de la revuelta agermanada, los tejedores de terciopelo menos pudientes desafían sin mayor éxito el monopolio de los cargos directivos por parte de los maestros acaudalados del gremio ${ }^{85}$. A la vez, en el transcurso de las Germanías, los torcedores de seda, subsumidos dentro del Art des Velluters y marginados de plano de la dirección gremial, comenzarán a bregar por constituir una corporación independiente. Estos artesanos están abocados a la torsión del

\footnotetext{
77 Deyá BauzÁ, La manufactura de la lana en Mallorca (1400-1700), p. 377.

78 Córdoba de la Llave, “Guild Authorities in Late Medieval Spain”, p. 84.

79 Menjot, "Los trabajos de la construcción en 1400”, p. 33.

80 GonzÁlez Arce, "La organización de la producción textil y las corporaciones gremiales”, pp. 730-1.

81 Martínez Vinat, “La comunidad de 'peraires' de la ciudad de Valencia”, 123; Deyá Bauzá, La manufactura de la lana en Mallorca (1400-1700), p. 375.

82 IRADIEL, "Corporaciones de oficio, acción política y sociedad civil en Valencia"; Martínez Vinat, "La comunidad de 'peraires' de la ciudad de Valencia".

83 Martínez Vinat, “La comunidad de 'peraires' de la ciudad de Valencia”, p. 124.

84 Deyá BAUZÁ, La manufactura de la lana en Mallorca (1400-1700), pp. 315-18.

85 García CÁrcel, Las Germanías de Valencia, p. 31.
} 
hilo de seda, abasteciendo de fibra a los velluters ${ }^{86}$. Los menestrales en cuestión no solo reclaman su autonomía institucional, sino que también defienden el derecho a discernir sobre las características de su proceso productivo. En concreto, como parte del pleito entablado para independizarse, estos artesanos reclaman la libertad para utilizar el torno de gorra para hilar en lugar del torno con devanadera que buscan imponer los terciopeleros. Aparentemente, este último torno produciría una fibra más acorde a las necesidades comerciales de la producción sedera ${ }^{87}$. En un contexto en el cual los torcedores de seda no han sido separados de los medios de producción, la estructura institucional de la corporación permite a los terciopeleros establecer las características fundamentales de las herramientas de estos artesanos. Los pelaires murcianos, como hemos visto, proceden de forma similar con respecto a los aparejos de los cardadores de lana.

Los torcedores logran constituir una corporación autónoma en 1520, trazando una trayectoria análoga a la de los cardadores de lana y tundidores murcianos, en cuanto oficios menores que logran emanciparse de una corporación mayor. Sin embargo, los menestrales valencianos no tendrán la suerte de estos últimos colectivos artesanales, dado que serán reabsorbidos por el Art des Velluters, luego de casi una década de pleitos ante las autoridades locales ${ }^{88}$.

En síntesis, puede observarse que en los casos mencionados la conflictividad intragremial se encuentra determinada por la contradicción entre un sector de artesanos acaudalados que tiende a monopolizar la dirección de la corporación y aquellos menestrales menos pudientes, que en la mayoría de los casos subsisten gracias a la venta de su fuerza de trabajo. En este sentido, sería lógico que el conflicto que nos ocupa haya sido impulsado por los asalariados de la corporación.

\section{La lucha por la veeduría, ¿qué tipo de conflicto?}

Para concluir este trabajo, retomamos la pregunta que hemos planteado en la introducción. ¿Cuál es la naturaleza social del conflicto en torno a las elecciones de veedores del gremio pelaire? Hemos demostrado que unas pocas familias de pelaires empresarios, los Roldán, Albacete, Serrano, Ruiz y de Castro, tienden a monopolizar la dirección del gremio. Ahora bien, año tras año, al momento de designar autoridades corporativas, el poder de estas familias es puesto en cuestión, lo que supone un momento de inestabilidad en la vida gremial. De ahí que el concejo de la ciudad impulse la modificación del criterio de elección de veedores, buscando, sin éxito, la fórmula que garantice la paz social.

Hemos planteado dos hipótesis sobre este conflicto. La primera es que este obedezca a una disputa propia del empresariado pelaire. Es decir, que los responsables de esta inestabilidad sean aquellos pelaires acaudalados que solo logran acceder de forma esporádica al cargo

\footnotetext{
86 Navarro Espinach, El Despegue de La Industria Sedera En La Valencia Del Siglo XV, p. 95.

87 Para los detalles técnicos ver Navarro Espinach e Iradiel, "La seda en Valencia en la Edad Media", p. 199.

88 García Cárcel, Las Germanías de Valencia, p. 33.
} 
de veedor. Sin embargo, esta propuesta presenta dos problemas. Por un lado, hemos visto que, independientemente de quién ejerza la veeduría, existe una continuidad en las disposiciones impulsadas desde la dirección gremial que apunta a garantizar la acumulación de capital por parte del empresariado pelaire. Por el otro, hemos señalado que el núcleo dirigente del gremio habría tenido incidencia directa en la designación como veedores de los pelaires provenientes de familias con menor peso político. La alternancia en el cargo, más que ser fruto del conflicto entre facciones del empresariado pelaire, obedecería a un proceso de rotación menos traumático en la dirección de la corporación. Esto no implica la inexistencia de conflictos, pero no basta para explicar semejante nivel de inestabilidad. La segunda hipótesis que planteamos es que la pugna en torno a la veeduría obedezca al corte horizontal que opera dentro de la corporación. En este sentido, serían los artesanos asalariados del gremio los grandes protagonistas del conflicto. Como hemos señalado, estos tienen poderosas razones para disputar la dirección del gremio, en tanto esta opera como una herramienta para garantizar su subsunción. Esta lucha solo se corrobora para los tundidores, aunque podemos conjeturar que los cardadores de lanas y paños hayan participado asimismo de la contienda. A la vez, esta es la lógica que impera en las disputas intragremiales de buena parte de las corporaciones castellanas y aragonesas. De ser así, la inestabilidad al interior del gremio sería producto de las contradicciones irreconciliables entre el empresariado pelaire y el conjunto heterogéneo de los asalariados que trabajan a su servicio. En otras palabras, es la lógica de lucha de clases la que mejor explica la potencia del conflicto.

\section{Bibliografía}

Asenjo GonzÁlez, María, "Transformación de la manufactura de los paños en Castilla: las Ordenanzas generales de 1500”, Historia. Instituciones. Documentos, 18 (1991), pp. 1-38. Córdoba de la Llave, Ricardo, "Guild Authorities in Late Medieval Spain", Craftsmen and Guilds in the Medieval and Early Modern Periods, Eva Jullien y Michel Pauly (eds.), Eva Jullien y Michel Pauly, Sttugart, 2016, pp. 77-92.

Córdoba de la Llave, Ricardo, Los oficios medievales: tecnología, producción, trabajo, Síntesis, Madrid, 2017.

Deyá BauzÁ, Miguel José, La manufactura de la lana en Mallorca (1400-1700): gremios, artesanos y comerciantes, Tesis doctoral inédita, 1997.

FARR, James, Artisans in Europe, 1300-1914, Cambridge University Press, Cambridge, 2000.

FAZZINI, Mauro, "La construcción de la hegemonía pelaire en la protoindustria textil murciana”, Sociedades Precapitalistas, 10, (2020), e046.

García CÁrcel, Ricardo, Las Germanías de Valencia, Península, Barcelona, 1975.

Gomariz Marín, Antonio. Colección de documentos para la historia del Reino de Murcia XX. Documentos de los Reyes Católicos (1492-1504), Academia Alfonso X el Sabio, Murcia, 2000. 
GonZÁlez Arce, José Damián, Gremios, producción artesanal y mercado: Murcia, siglos XIV y XV, Universidad de Murcia, Murcia, 2000.

GonZÁlez ArCE, José Damián, “La organización de la producción textil y las corporaciones gremiales en las ordenanzas generales de paños castellanas (1494-1511)", Anuario de Estudios Medievales, 38/2 (2008), pp. 707-759.

GonzÁlez Arce, José Damián, "Los gremios contra la construcción del libre mercado. La industria textil de Segovia a finales del siglo XV y comienzos del XVI", Revista de Historia Industrial, 42 (2010), pp. 15-42.

IrADIEL, Paulino, Evolución de la industria textil castellana en los siglos XIII-XVI. Factores de desarrollo, organización y costes de la producción manufacturera de Cuenca, Universidad de Salamanca, Salamanca, 1974.

IRADIEL, Paulino, "Corporaciones de oficio, acción política y sociedad civil en Valencia", El mediterráneo medieval y Valencia: Economía, sociedad, historia, Paulino Iradiel (comp.), PUV, Valencia, 2017, pp. 289-321.

Martínez Martínez, María, La industria del vestido en Murcia (siglos XIII-XV), Academia Alfonso X el Sabio, Murcia, 1988.

Martínez Martínez, María, Documentos relativos a los oficios artesanales en la baja Edad Media, Colección de Documentos para la Historia del Reino de Murcia XXI, Academia Alfonso X el Sabio, Murcia, 2000.

Martínez MartíneZ, María, "El poder representado y la representación del poder: Fiestas Urbanas (Murcia, ss. XIII-XV)", Estudios sobre Patrimonio, Cultura y Ciencias Medievales, 16 (2014), pp. 201-248.

MARTínez VinAt, Juan, “La comunidad de 'peraires' de la ciudad de Valencia: de la disgregación a la unión confraternal (1340-1511)”, En la España Medieval, 42 (2019), pp. 111-135.

Menjot, Denis, "Los trabajos de la construcción en 1400: primeros enfoques", Miscelánea medieval murciana, 6 (1980), pp. 9-56.

Molina Molina, Ángel Luis, "Datos sobre sociodemografía murciana a fines de la edad media (1475-1515)", Anales de la Universidad de Murcia. Filosofía y Letras, 36, n 1-2 (1977-8), pp. 169-83.

Navarro Espinach, Germán, El Despegue de La Industria Sedera En La Valencia Del Siglo XV, Consell Valencià de Cultura, Valencia, 1992.

Navarro Espinach, Germán e Iradiel, Paulino, "La seda en Valencia en la Edad Media", España y Portugal en las rutas de la seda : diez siglos de producción y comercio entre Oriente y Occidente, Publicacions Universitat de Barcelona, Barcelona, 1996, pp.181-200.

RiERA i Melis, Antoni, "La aparición de las corporaciones de oficio en Cataluña (12001350)", Cofradias, gremios y solidaridades en la Europa medieval / XIX Semana de Estudios Medievales, Estella, 20 a 24 de julio de 1992, Fondo de publicaciones del Gobierno de Navarra, Pamplona, 1993, pp. 285-318. 